\title{
Morphometric Evaluation of the Foramen Magnum in a Sri Lankan Population
}

\author{
Peiris R ${ }^{1}$, Vadysinghe ${ }^{2}$, Nanayakkara $\mathrm{D}^{1}$ \\ 'Division of Anatomy, Department of Basic Sciences, Faculty of Dental Sciences, \\ University of Peradeniya, Sri Lanka. \\ ${ }^{2}$ Department of Forensic Medicine, Faculty of Medicine, University of Peradeniya, Sri \\ Lanka
}

\begin{abstract}
Objective: The foramen magnum (FM) that transmits a large number of vital structures is an important anatomical landmark in neurosurgical procedures and forensic anthropology. The aim of the present study was to determine the dimensions and shape of the FM in a Sri Lankan population. Material and method: Forty-four adult skulls (32 males and 12 females) were selected for the study. Sagittal (FMSD) and transverse (FMTD) diameters of the FM were taken using a sliding digital vernier caliper to the nearest $0.01 \mathrm{~mm}$ by one investigator. The area of the FM was calculated using Radinsky's formula; $\mathrm{A}=1 / 4$ X 3.14 X FMTD X FMSD and FM index was calculated using the formula: FMTD x $100 /$ FMSD. The skulls were visually assessed to determine the shape of the FM. The shape of the FM was recorded as round, oval, egg-shaped, tetragonal, pentagonal, hexagonal or irregular.
\end{abstract}

Results: The mean sagittal and transverse diameter, area and index of the foramen magnum in males were $34.62 \pm 2.17 \mathrm{~mm}, 29.52 \pm 2.13 \mathrm{~mm}$, $695.77 \pm 90.64 \mathrm{~mm} 2$ and $85.41 \pm 5.66$, respectively, whereas they were
$33.87 \pm 2.31 \mathrm{~mm}, 28.28 \pm 1.99 \mathrm{~mm}$, $662.56 \pm 98.67 \mathrm{~mm}^{2}$ and $83.69 \pm 6.13$, respectively, in females. The shape of the foramen was found to be eggshaped in $34.1 \%$, and round in $27.2 \%$ of the cases.

Conclusions: The size and shape of the foramen magnum are highly variable among different world populations. Sri Lankan skulls showed smaller foramen magnum in compare with those of African, Mediterranean and European populations. Males displayed larger mean values than females for all measured variables.

Key Words: Foramen Magnum, Morphometry, Population difference, Sexual dimorphism

\section{Introduction}

The basicranium forms in a zone of interaction between structures with neural, skeletomotor, respiratory, auditory, masticatory, digestive, and visual functions. Because of the complex structural-functional relationships in the region, the morphology of the basicranium shows compromises resulting from the 
competing demands of multiple soft tissue units. For example, during basicranium development, the structures traversing the endocranialectocranial boundary become encircled by cartilage and eventually by bone. The resulting bony foramina of the basicranium respond in an idiosyncratic but bilaterally symmetrical fashion to changes in the size and positioning of enclosed soft tissues [1].

The basicranium is complex, and the Foramen Magnum (FM), is the large opening in the posterior part of the cranial base, through which the cranial cavity communicates with the vertebral canal. It is situated at the craniovertebral junction and is oval, and wider behind with its greatest diameter being the anteroposterior [2]. It transmits many vital structures like the lower end of the medulla oblongata, meninges, vertebral arteries and spinal accessory nerve [2] and therefore, considered as an important landmark. Anteriorly, the margin of the FM is slightly overlapped by the occipital condyles which project down to articulate with the superior articular facets on the lateral masses of the atlas [2].

An awareness of the normal dimensions of the FM is clinically important as certain developmental and acquired craniovertebral junction disorders such as achondroplasia [3,4], craniometaphyseal dysplasia [5] assimilation of axis [6], and Jeune's asphyxiating thoracic dystrophy $[7,8]$ associated with the FM resulting in variations in its morphometry. Besides its clinical importance, FM dimensions have also been used as significant criteria in sex determination in forensic investigations [9]. Recent studies report that morphometry is a fast and efficient method for the evaluation of demographic characteristics, such as ethnicity, gender, age, etc. Evidence suggests that the shape and dimensions of the FM exhibit sex dimorphism and population based variations [9-19]. Therefore, the shape and dimensions of the FM and their variations have been reported to be of diagnostic, anthropological, forensic and clinical importance [12]. Furthermore, FM dimensions are commonly used in anthropology and forensic investigations because FM with its surrounding cranial base can withstand physical damage than any other areas of the cranium as it is situated in relatively protected anatomical location with large masses of soft tissue over it [20].

Although the morphometry and shape of the FM have been studied with reference to various human population groups [9-19,21], to the best of our knowledge, none has been documented in the literature for Sri Lankans, despite its anatomical, anthropological and clinical relevance. Hence, the current study was conducted to determine the dimensions and shape of the FM in a Sri Lankan population, make comparisons with other population groups and investigate the sexual dimorphism of FM morphology. 


\section{Materials and Methods}

Fifty-seven dry human skulls from the Division of Anatomy, Department of Basic Sciences, Faculty of Dental Sciences, University of Peradeniya, Sri Lanka were assembled for this study. The sex and age of all skulls were retrieved from the personal records of body donors. The skulls with no apparent gross pathology, deformity, or traumatic lesions were included in the study. Criteria of exclusion were those in which the margins of the foramen magnum could not be clearly identified owing to breakage and those with deformities and trauma affecting the landmarks for measurement. Forty-four adult skulls 32 males and 12 females were selected for the study. Approval for this study has been granted by the Faculty Research Committee of the Faculty of Dental Sciences, University of Peradeniya (FDS-FRC/2014/06) and therefore, the study has been performed in accordance with the ethical standards laid down in the 1964 Declaration of Helsinki and all subsequent revisions.

The measurements were taken using a sliding digital vernier caliper to the nearest $0.01 \mathrm{~mm}$. The following measurements of the FM were recorded adopting the landmark definitions described in previous studies [12,19];

1. Sagittal diameter (FMSD) - the distance between the basion and opisthion (Figure 1). Basion and opisthion are the points where the midsagittal plane intersects the anterior margin and the posterior margin of the FM, respectively
2. Transverse diameter (FMTD) - the distance between the lateral margins of FM at the point of maximum lateral curvature (Figure 1)

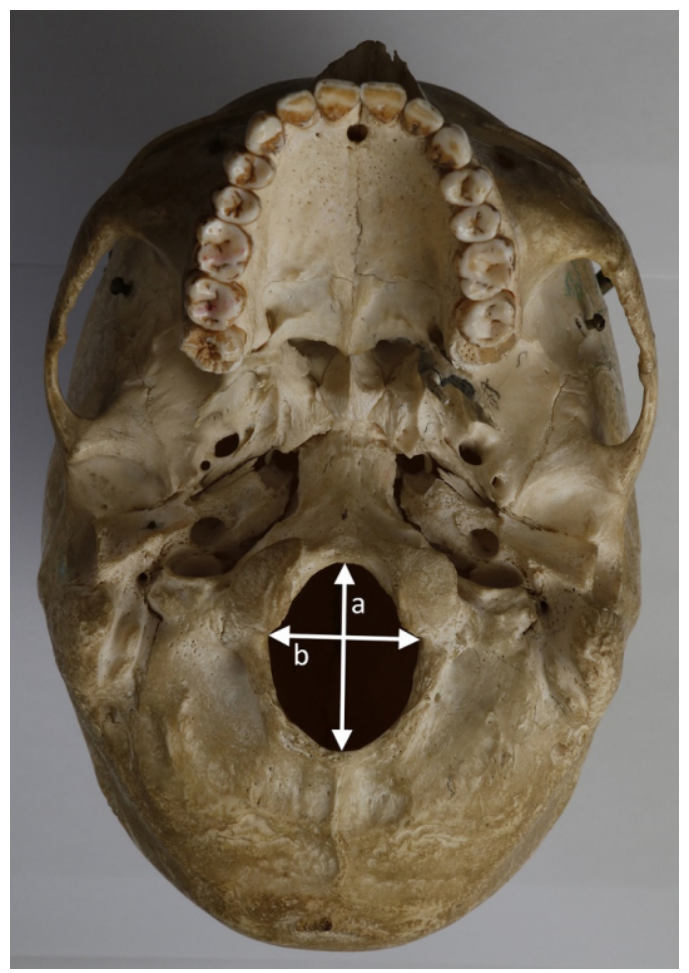

Figure 1. Measurements of the foramen magnum: (a) Foramen Magnum sagittal diameter (FMSD), (b) Foramen Magnum transverse diameter (FMTD)

The area of the foramen magnum (FMA) was calculated using Radinsky's formula; A=1/4 X 3.14 X FMTD X FMSD [22]. Additionally, the index of FM (FMI) was calculated by using the formula: FMTD x 100 / FMSD.

The skulls were visually assessed to determine the shape of the FM. The shape of the FM was recorded as round, oval, egg-shaped, tetragonal, pentagonal, hexagonal or irregular as described by Murshed et al. [12] (Figure 2). 


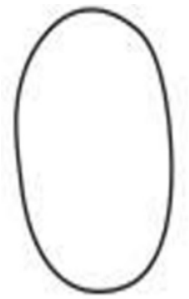

a

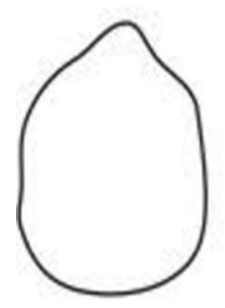

e

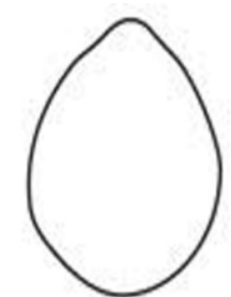

b

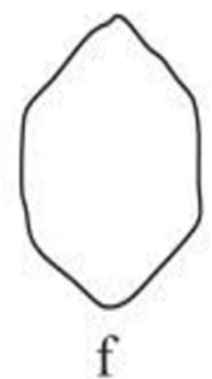

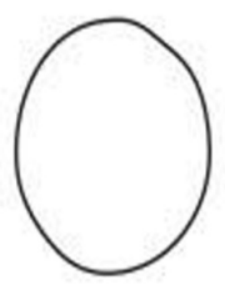

c

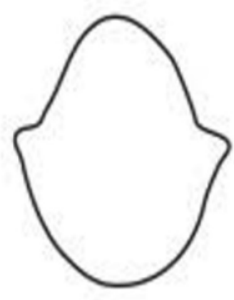

g
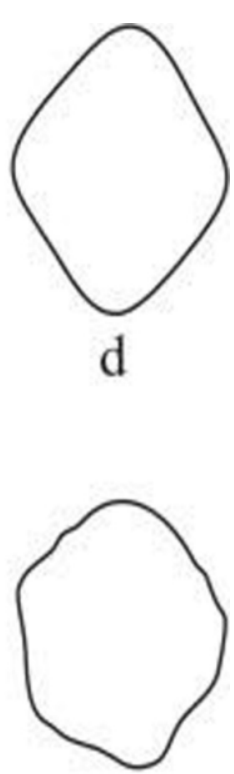

$\mathrm{h}$

Figure 2. Foramen magnum shape variations

(A) Oval type; (b) Egg type; (c) Round type; (d) Tetragonal type; (e) Pentagonal type;

(f) Hexagonal type; (g) Irregular type A; (h) irregular type B

All measurements and observations on the shape were recorded by one investigator. In order to minimize the intra observer error three repeated measurements were made for each parameter at different sittings with 1week interval between sittings, and the average of the three measurements was taken for further analysis.

Results were expressed as means and SDs and the differences in the measurements between male and female were analyzed using the Statistical Package for Social Sciences (SPSS), 19th version. Students' t-test was used for the analysis and $p<0.05$ was considered as statistically significant.

\section{Results}

Descriptive statistics with values of the minimum, maximum, means and standard deviations of all measurements of the FM of males and females are presented in Table 1. Average age of the skulls in the present study was 65.25 years. Therefore, FM size and shape are considered to be fully established and age was not considered for further analysis. It is evident that males display larger mean values than females for all measured variables of the FM. Especially, the FMTD in male skulls varied between $24.24-33.48 \mathrm{~mm}$ with a mean of $29.74 \mathrm{~mm}$, while in females the FMTD varied from $25.73-31.76 \mathrm{~mm}$ with a mean of $28.28 \mathrm{~mm}$. The difference was statistically significant $(p<0.05)$. 
Although FMA was larger in males than in females the differences were not statistically significant. In addition, the mean FMI was higher in males $(85.41 \pm 5.66)$ compared to females $(83.69 \pm 6.13)$.

Table 1. Basic statistics of the FM dimensions and index in males and females

\begin{tabular}{|c|c|c|c|c|c|}
\hline \multirow[t]{3}{*}{ Measurement } & \multicolumn{2}{|c|}{ Males $(n=32)$} & \multicolumn{2}{|c|}{ Females $(n=12)$} & \multirow[t]{3}{*}{ Difference } \\
\hline & Range (mm) & Mean \pm SD & Range & Mean \pm SD & \\
\hline & & (mm) & $(\mathrm{mm})$ & $(\mathrm{mm})$ & \\
\hline FMSD & $30.18-39.86$ & $34.62 \pm 2.17$ & $30.88-37.47$ & $33.87 \pm 2.31$ & NS \\
\hline FMTD & $25.62-33.48$ & $29.52 \pm 2.13$ & $25.73-31.76$ & $28.28 \pm 1.99$ & * \\
\hline \multirow[t]{2}{*}{ FMA } & $608.67-$ & $695.77 \pm 90.64$ & $519.84-$ & $662.56 \pm 98.67$ & NS \\
\hline & 901.44 & & 867.56 & & \\
\hline FMI & $68.80-94.62$ & $85.41 \pm 5.66$ & $69.59-95.56$ & $83.69 \pm 6.13$ & NS \\
\hline (FMTD/FMSI & & & & & \\
\hline
\end{tabular}

$* \mathrm{P}<0.05 ; \mathrm{NS}$, Not Significant

FMSD; Foramen Magnum Sagittal diameter, FMTD; Foramen Magnum Transverse diameter, FMA; Foramen Magnum Area, FMI; Foramen Magnum Index

We combined the male and female data to analyze the shape of FM because the shape difference between the two was not statistically significant. The various shapes of the FM observed in the present study are shown in Table 2.

Table 2. Frequency of different shapes of FM

\begin{tabular}{lc}
\hline \multicolumn{1}{r}{ Shape of foramen magnum } & Frequency $(\%)$ \\
\hline Egg & 34.1 \\
Round & 27.2 \\
Oval & 13.6 \\
Tetragonal & 13.6 \\
Irregular & 9.1 \\
Hexagonal & 2.3 \\
\hline
\end{tabular}




\section{Discussion}

In any attempt to figure out the population differences of FM morphology it is important to consider about the development pattern of the basicranium because it makes us understand the balance between genetic and environmental contribution on its development in different world populations. It is evident that in the early foetal stages the size of the brain stem increases relative to the cerebrum and cerebellum. Therefore, the youngest foetuses have a voluminous brain stem relative to the size of the cerebellum. This growth pattern results in a larger FM being associated with a small cranial vault in early foetal stages [23]. However, Richards and Jabbour [24] showed that this relationship is restricted only to early foetal stages because growth increases are minor in late foetal stages relative to the increases observed in the cranial vault. It has also been confirmed that the brain stem completes the majority of its growth at the termination of the first year of life and brain size doubles during this time period [25]. In addition, the rates of growth in breadth of both the FM and the cranial vault which dominated early in the development stabilize while lengths continue to increase slowly during 1-3 years of age. After 3 years of age FM has completed most of its growth while the cranial vault continues to increase [24]. This confirms that pattern of increase in FM length and breadth vary during foetal life and even during the first year after birth. However, FM sizes and shapes tend to vary throughout the ontogenetic sequence and these variations are correlated with the changes in the brain size and cranial capacity during the growth period and also linked to specific cranial morphologies [24].

In the meantime, Smith and Beals [26] explained the association between cranial capacity and latitude showing larger cranial capacity with more rounded head in people habitat in cold climates. They further emphasised the association between the cranial capacity and body size with large cranial capacity with increasing body size. This is further supported by a study done by Gonda et al. [27] on association of brain size and environmental factors in nine-spined sticklebacks. They reported that variation among tested populations of wild nine-spined sticklebacks is large, both in terms of brain size and in the size of separate brain parts.

Furthermore, the incongruence between the wild and common garden patterns suggested that much of the population variation found in the wild may be attributable to environmentally induced phenotypic plasticity.

These evidence suggest that FM size and shape may vary among different world human populations and both genetic and environmental factors contribute for these differences. In addition, it is affirmed that FM shape and size are correlated with the brain size, cranial capacity, and specific hemodynamic, hydrodynamic and locomotor functions in the region and the structural-functional relationships 
between some of these are modified during ontogeny. This is further emphasized by the present study which shows clear population variation in both FM size and shape (Table 3).

Table 3. Comparison of FM diameters of the present sample and with those of other

\begin{tabular}{lllll}
\hline Population & FMSD $(\mathrm{mm})$ & \multicolumn{3}{l}{ FMTD $(\mathrm{mm})$} \\
\hline & Male & Female & Male & Female \\
\hline Turkey [12] & $37.2 \pm 3.43$ & $34.6 \pm 3.16$ & $31.6 \pm 2.99$ & $29.3 \pm 2.19$ \\
Britain [19] & $35.91 \pm 2.41$ & $34.71 \pm 1.91$ & $30.51 \pm 1.77$ & $29.36 \pm 1.96$ \\
Spain [13] & $36.2 \pm 0.3$ & $34.6 \pm 0.4$ & $31.1 \pm 0.3$ & $29.6 \pm 0.3$ \\
Brazil [14] & $36.5 \pm 2.6$ & $35.6 \pm 2.5$ & $30.6 \pm 2.5$ & $29.5 \pm 1.9$ \\
Iran [15] & $37.72 \pm 1.01$ & $34.37 \pm 1.47$ & $31.67 \pm 1.27$ & $28.34 \pm 1.4$ \\
Poland [29] & $36.89 \pm 3.17$ & $34.76 \pm 2.96$ & $32.47 \pm 3.08$ & $30.96 \pm 3.01$ \\
India [30] & $35.5 \pm 2.8$ & $29.6 \pm 1.9$ & $32.0 \pm 2.8$ & $27.1 \pm 1.6$ \\
Nigeria [16] & $36.36 \pm 2.3$ & $34.39 \pm 3.88$ & $30.9 \pm 2.5$ & $28.16 \pm 1.9$ \\
Kenya [28] & 40.0 & 34.0 & 38.0 & 28.0 \\
Sri Lanka (Present study) & $34.50 \pm 2.16$ & $33.87 \pm 2.31$ & $29.74 \pm 1.98$ & $28.28 \pm 1.99$ \\
\hline
\end{tabular}

FMSD; Foramen Magnum Sagittal diameter, FMTD; Foramen Magnum Transverse diameter

Interestingly, the mean values of FM dimensions of Sri Lankans are lower than those reported for Brazilian, Turkish, Spanish, Iranian, Nigerian, Kenyan and British populations (Table 3). Loyal et al. [28] showed that Kenyans demonstrated a large FM having FMSD, 40mm and FMTD, 28mm in males. This is followed by Mediterranean, Middle east and European populations who showed moderately larger FM. Murshed et al. [12] reported that FMSD, FMTD and FMA as $37.2 \mathrm{~mm}, 31.6 \mathrm{~mm}$ and $931 \mathrm{~mm}^{2}$ in males and $34.6 \mathrm{~mm}, 29.3 \mathrm{~mm}$ and $795 \mathrm{~mm}^{2}$ in females, respectively in a Turkey population. Meanwhile, for an Iranian population Kazemzadeh et al. [15] showed that FMSD as $37.72 \mathrm{~mm}$ and $34.37 \mathrm{~mm}$ and FMTD as $31.67 \mathrm{~mm}$ and $28.34 \mathrm{~mm}$ for males and females, respectively. In a similar study Burdan et al. [29] showed that FMSD and FMTD as $36.89 \mathrm{~mm}$ and $32.47 \mathrm{~mm}$ in males and $34.76 \mathrm{~mm}$ and $30.96 \mathrm{~mm}$ in females, respectively with FMA having $881 \mathrm{~mm}^{2}$ and $765 \mathrm{~mm}^{2}$ in males and females, respectively in a Poland population. In the meantime, FM dimensions of the present study in a Sri Lankan population were less than $35 \mathrm{~mm}$ in males and $30 \mathrm{~mm}$ in females in all 
parameters with FMA having less than $700 \mathrm{~mm}^{2}$ in both the sexes. However, FM dimensions of Indian populations showed close affinities with those of Sri Lankans [30]. These differences may be attributed to genetic, environmental or socio-economic differences among these population groups. The broad range of variation demonstrated in relation to FM sizes emphasize the importance of establishing populations specific values as those established for one population group may not be applicable to another population group.

Previous studies of FM shape have shown it to be oval in infant and oval to round in adults. Rates and patterns of fetal growth are in accord with FM elongation and its oval shape [31]. Postnatal growth rates and patterns were found to result in increased breadths, reduced growth in length, and a general tendency for a broadening of the FM. Growth increases in the FM mostly occur at the interocciptal synchondroses anterior and posterior and neither the positioning nor the growth patterns of these synchondroses are such as to promote evenly distributed breadth increases [32]. Therefore, in general, the tendency during postnatal growth is for foramina to become ventrally wide, not circular [24].

Standard texts of anatomy describe the foramen magnum to be usually oval in shape [2]. Although this is in agreement with the majority of skulls, it ignores a large body of evidence regarding the other shapes of the FM present among different populations. In the present study, majority of the FM were either egg shaped $(34.1 \%)$ or round $(27.2 \%)$. In a Turkish population, Murshed et al. [12] observed oval shaped FM less frequently, $8.1 \%$ and more occurrence of round $(21.8 \%)$, irregular $(20 \%)$, and hexagonal (17.2\%) shapes. In the meantime, Zaidi and Dayal [33] reported that $64 \%$ of the FM was oval in shape in an Indian population. Interestingly, Loyal et al. [28] analyzing 202 skulls of Kenyans reported the shape of the FM to be polygonal in $63 \%$ of the cases. It is evident from these studies that there is great variation regarding the predominant morphological type of FM among different world population groups and these differences are related to brain size, cranial capacity, specific hemodynamic, hydrodynamic and locomotor functions in the region and even genetic differences of these populations.

The FMI derived from the sagittal and transverse diameters is a measure of the foramen shape [24]. Moreover, the index is also helpful in distinguishing oval-like or round-like types of foramina [29]. The round-like form is characterized by the index 0.9-1.1 (90$110 \%$ ), while foramina with a value below or above it is called as longitudinal and horizontal oval like ones, respectively [29]. The FMI of the present study was $85.41 \pm 5.66$ in males and $83.69 \pm 6.13$ in females which is indicative of the longer FMSD in the skulls of the present study.

As the fusion of the bony elements forming the FM completes early in life 
it is unlikely to respond to any significant secondary sexual changes [19,34]. Moreover, as the nervous system attains maturity at a very young age there is no requirement for an increase in size. Sex dimorphic characteristics in the FM region must therefore occur during an early stage of development at a time when other skeletal elements have not attained sexspecific traits [19,24]. This feature of the FM is significant in gender determination in young individuals using FM parameters.

All measured variables of the FM have been reported to be greater in males than in females in almost all previous studies [9-19,21]. However, the level of significance observed in the sex differences varies in different studies. These differences observed in various studies have been attributed to the diverse ethnic groups involved and to the variations in methodology and statistical analyses adopted [11,17]. In the present study, males displayed larger FM dimensions than the females. However, statistically significant difference between the sexes was seen only for the measurement of FMTD $(p<0.05)$. Although this finding is consistent with that of Macaluso Jr.

[11] in a French sample and Vedanayagam and Sathyamurthy [18] in an Indian population, it contrasts with the results presented in similar investigations on diverse populations, including the Nigerian [16], Spanish [13], Indian [17], Turkish [12], Brazilian [21] and the historic British sample from St. Bride's Church [19], where males exhibited significantly larger dimensions than females, not only for the FMTD, but also for the FMSD and area of the FM. Contrary to these views, in studies of Gruber et al. [10], Tubbs et al. [6] and Loyal et al. [28], the diameters of the FM did not display any significant sexual dimorphism. Gruber et al. [10] attributed this difference to the smaller sample size and greater variability in dimensions in their study on Central European dry specimens dating from Pleistocene to modern times. Furthermore, in the present analysis, the mean FMA was higher in males is than in females. This is in accordance with the findings reported in preceding studies [9,11,12,17,28] (Table 4). However, in contrast to their findings, the difference between the means of males and females was not statistically significant in our study. Uthman et al. [9] reported that the FMA could be used in sex determination with an overall accuracy of $69.3 \%$. Discriminant function analyses carried out in previous studies have demonstrated varying degrees of sex predictability by these dimensions of the FM. Hence, it is the view of many authors that the measurements of the foramen should be used in conjunction with other sexing evidence available to ascertain the sex of unidentified individuals $[17,19,21]$. In the meantime, it should be noted that smaller female sample size is one of the limitations of the present study and future studies with larger sample is recommended to make concrete conclusions. 
Table 4. Comparison of FMA of the present sample and with those of other populations as reported in previous studies

\begin{tabular}{lll}
\hline \multicolumn{1}{c}{ Population } & \multicolumn{2}{c}{ FMA (mm²) } \\
\hline Turkey [12] & Male & Female \\
Iraq [9] & 931 & 795 \\
South India [17] & 765 & 670 \\
France [11] & 705 & 622 \\
Poland [29] & 854 & 807 \\
South India [35] & 881 & 765 \\
Sri Lanka (Present study) & 748 & 711 \\
\hline
\end{tabular}

FMA; Foramen Magnum Area

\section{Conclusion}

This study presents valuable reference data regarding the shape and morphometry of the FM of an adult Sri Lankan population which indeed will be of great anthropological, forensic and clinical interest. The size and shape of the foramen magnum are highly variable among different world populations. Sri Lankan skulls showed smaller foramen magnum in comparison with those of African, Mediterranean and European populations. The sex dimorphic measurements of the foramen may be used in conjunction with other sexing evidence available to ascertain the sex of bony fragments of unidentified individuals.

\section{Acknowledgements}

The authors wish to thank Mr. D. Ihalagedera, Mr. M. Ratnayaka, Mr. W. A. S. Bandula, Mr. A. G. Mahindapala, Mr. W. H. M. Ananda, Mr. D. K. G. D. S. B. Wijerathna and Mr. D. W. D. Dissanayaka, Division of Anatomy, Department of Basic Sciences, Faculty of Dental Sciences, University of Peradeniya, for the technical support provided.

\section{Correspondence to -}

Professor Roshan Peiris

Division of Anatomy, Department of

Basic Sciences, Faculty of Dental Sciences, University of Peradeniya, Peradeniya, 20040, Sri Lanka

E-mail : rdpeiris@gmail.com, rdpeiris@pdn.ac.1k

Tel: 94-81-2397236

Fax: 94-81-2388948 


\section{References}

1. Berge JK, Bergman RA. Variation in size and in symmetry of foramina of the human skull. Clin Anat 2001;14:406-413.

2. Standring S. Gray's Anatomy: Anatomical Basis of Clinical Practice. 39th ed. Churchill Livingstone Elsevier, London, UK; 2008.

3. Bagley CA, Pindrik JA, Bookland MJ, Camara-Quintana JQ, Carson BS. Cervicomedullary decompression for foramen magnum stenosis in achondroplasia. J Neurosurg. 2006;104(3):166-72.

4. Hecht JT, Horton WA, Reid CS, Pyeritz RE, Chakraborty R. Growth of the foramen magnum in Achondroplasia. Am J Med Genet. 1989;32(4):528-535.

5. Boltshauser E, Schmitt B, Wichmann W, Valavanis A, Sailer $\mathrm{H}$, Yonekawa $\mathrm{Y}$.

Cerebellomedullary compression in recessive craniometaphyseal dysplasia, Neuroradiology. 1996;38:193-195.

6. Tubbs RS, Griessenauer CJ, Loukas M, Shoja MM, Cohen- Gadol AA. Morphometric analysis of foramen magnum: an anatomic study. Neurosurg. 2010;66(2):385-388.

7. Kanodia G, Parihar V, Yadav YR, Bhatele PR, Sharma D. Morphometric analysis of posterior fossa and foramen magnum. $\mathrm{J}$ Neurosci Rural Pract. 2012;3:261266.
8. Knisely AS, Steigman CK. Stenosis of the foramen magnum and rostral spinalcanal, with spinal cord deformity in Jeune's asphyxiating thoracic dystrophy. Pediatr Pathol. 1989;9(3):299-305.

9. Uthman AT, Al-Rawi NH, AlTimimi JF. Evaluation of foramen magnum in gender determination using helical CT scanning. Dentomaxillofac Radiol. 2012;41(3):197-202.

10. Gruber P, Henneberg M, Boni T, Ruhli FJ. Variability of human foramen magnum size. Anat Rec. 2009;292:1713-1719.

11. Macaluso Jr. PJ. Metric sex determination from the basal region of the occipital bone in a documented French sample. Bull Mem Soc Anthropol Paris. 2011;23:19-26.

12. Murshed KA, Çiçekcibaşi AE, Tuncer I. Morphometric evaluation of the foramen magnum and variations in its shape: a study on computerized tomographic images of normal adults. Turk J Med Sci. 2003;33:301-306.

13. Catalina - Herrera CJ. Study of the anatomic metric values of the foramen magnum and its relation to sex. Acta Anat (Basel). 1987;130:344-347.

14. Suazo GIC, Russo PP, Zavando MDA, Smith RL. Sexual dimorphism in foramen magnum dimensions. Int J Morphol. 2009;27(1):21-23. 
15. Kazemzadeh N, Aghakhani K, Soltani S, Ghafurian F, Soltani B. Gender determination using diagnostic values of foramen magnum. Int J Med Toxicol and Forensic Med. 2016;6(1):29-35.

16. Ukoha U, Egwu OA, Okafor IJ, Anyabolu AE, Ndukwe GU, Okpala I. Sexual dimorphism in the foramen magnum of Nigerian adults. Int J Biol Med Res. 2011;2:878-881.

17. Kamath VG, Asif M, Shetty R, Avadhan R. Binary logistic regression analysis of foramen magnum dimensions for sex determination. Anat Res Int. 2015; doi.org/10.1155/2015/459428

18. Vedanayagam T, Sathyamurthy V. Sex determination from foramen magnum measurements -aregional study in Chennai, TN. Ind J Forensic and Community Med. 2015;2(3):179-181.

19. Gapert R, Black S, Last J. Sex determination from the foramen magnum: discriminant function analysis in an eighteenth and nineteenth century British sample. Int J Legal Med. 2009;123(1):25-33.

20. Holland TD. Sex determination of fragmentary crania by analysis of crania base. Am J Phys Anthropol. 1986;70:203-208.

21. Manoel CI,.Prado FB, Caria PHF, Groppo FC. Morphometric analysis of the foramen magnum in human skulls of Brazilian individuals: its relation to gender. Braz J Morphol Sci. 2009;26(2):104-108.

22. Radinsky L. elative brain sizw: a new measure. Science. 1967; 155:836-838.

23. Ford HER. Growth of the foetal skull. J Anat. 1956;90:63-72.

24. Richards GD, Jabbour RS. Foramen magnum ontogeny in Homo sapiens: a functional matrix perspective. Anat Rec (Hoboken). 2010;294(2):199-216.2011. doi: 10.1002/ar.21319.

25. Dunn HL. The growth of the central nervous system in the human foetus as expressed by graphic analysis and empirical formulae. J Comp Neurol. 1921;33:405-491.

26. Smith CL, Beals KL. Cultural Correlates with Cranial Capacity. Am Anthropol. 1990;92(1):193-200 doi: 10.1525/aa.1990.92.1.02a00150

27. Gonda A, Herczeg G, Merilä J. Population variation in brain size of nine-spined sticklebacks (Pungitius pungitius) - local adaptation or environmentally induced variation? BMC Evol Biol. 2011;11:75. doi.org/10.1186/1471-2148-11-75

28. Loyal P, Ongeti K, Pulei A, Mandela P, Ogeng'o J. Gender related patterns in the shape and dimensions of the foramen magnum in an adult Kenyan population. Anat J Afr. 2013;2:138-141. 
29. Burdan F, Szumito J, Walocha J, et al. Morphology of the foramen magnum in young Eastern European adults. Folia Morphol (Warsz). 2012;71(4):205-216.

30. Routal RR, Pal GP, Bhagwat SS, Tamankar BP. Metrical studies with sexual dimorphism in foramen magnum of human crania. J Anat Soc India. 1984;2:85-89.

31. Coqueugniot H. Le crâne d'Homo sapiens en Eurasie: Croissance et variation depuis 100,000 ans, Technical Report 822. Brit Arch Rep, International Series; 1999.

32. Richards GD. Basicranial ontogeny and evolution in Homo sapiens.
PhD Dissertation, University of California, Berkeley, Berkeley, CA; 2007.

33. Zaidi SH, Dayal SS. Variations in the shape of foramen magnum in Indian skulls. Anat Anz Jena. 1988;67:338-340.

34. Edwards K, Viner MD, Schweitzer W, Thali MJ. Sex determination from the foramen Magnum. J Foren Radiol Imag. 2013;1(4):186-192.

35. Shepur MP, Magi M, Nanjundappa B, Havaldar PP, Gogi P, Saheb SH, Morphometric analysis of foramen magnum. Int J Anat \& Res, 2014; 2:249-255. 